\title{
Thyroid Cancer pN1b TNM Finding v6
}

National Cancer Institute

\section{Source}

National Cancer Institute. Thyroid Cancer pN1b TNM Finding v6. NCI Thesaurus. Code C60875.

Thyroid cancer with metastasis to unilateral, bilateral or contralateral cervical or superior mediastinal lymph nodes. (from AJCC 6th Ed.) 